* Mestrando em Direito pela Universidade Católica de Brasília. Especialista em Direito pela Universidade do Sul de Santa Catarina. Procurador da República.

henriquegentil@yahoo.com. br

** $\mathrm{PhD}$ in Law, pela University of Aberdeen, UK. Doutor em Direito pela UFSC. Mestre em Filosofia, pela UFG. Professor da graduação e do mestrado em Direito da Universidade Católica de Brasília. Pesquisador colaborador do Instituto de Psicologia da UnB. Procurador da Fazenda Nacional.

juliocesar.deaguiar@gmail. com

\section{Novos Paradigmas da Cooperação JURídica INTERNACIONAL E O CONCEITO ConTEMPORÂNEO de SobERANIA}

New PARAdigms of INTERNATIONAL LegaL COOPERATION AND THE CONTEMPORANY OF SOVEREIGNTY

\section{Henrique Gentil Oliveira* Julio Cesar de Aguiar**}

Como citar: OLIVEIRA, Henrique Gentil. AGUIAR, Julio Cesar de. Novos paradigmas da cooperação jurídica internacional e o conceito contemporâneo de soberania. Revista do Direito Público, Londrina, v. 12, n. 2, p. 77-103, ago. 2017. DOI: $10.5433 / 1980-511 X .2017 v 12 n 2 p 77$

Resumo: Inicialmente, o artigo fará breve digressão histórica da recente ampliação de rumos da cooperação jurídica internacional, analisando como a efervescência com que pessoas e riquezas se deslocaram pelo mundo no século XX potencializou o surgimento de problemas que não podem ser solucionados solitariamente por um Estado, fazendo com que a soberania - a princípio, um mecanismo de isolamento, passasse a aproximar nações com propósitos comuns. Em sequência, mostrará que a forma como modernamente a aplicação do Direito Internacional soluciona as problemáticas transfronteiriças impôs à cooperação jurídica internacional transitar do singelo papel de instrumentalizar o Direito Penal Internacional 
para ser uma ferramenta essencial para a satisfação de direitos humanos, inclusive com o desenvolvimento de tratados para amparar a nova tarefa, abordando-se alguns deles. Continuando, evidenciará que o "mundo das soberanias" caminha para um "mundo das pessoas", e que a definição contemporânea de soberania encerra o dever cogente de cooperar. Finalizará o raciocínio expondo que enrijecer a soberania para obstar a cooperação certamente enfraquecerá a aptidão dos Estados de controlar o que acontece em seus territórios, e, por consequência, suas soberanias.

Palavras-chave: Cooperação jurídica internacional. Soberania. Direitos humanos. Novos paradigmas.

Abstract: Initially, the paper will do a brief historical tour of the recent expansion of the application of international legal cooperation, analyzing how the fast moving of people and richness around the world in the twentieth century increased the number of problems that cannot be solved by a state on it's own, making sovereignty - at first, an isolation mechanism - connect nations with common purposes. In sequence, will show how the incidence of the modern international law in the resolution of some border problems forced international legal cooperation to transform itself from a simple tool of the International Criminal Law into an essential tool for the satisfaction of human rights, with the development of treaties 
to support the new task, analysing some of those treaties. Continuing, the paper is going to reveal that the "world of sovereignties" is becoming a "world of people" and that the contemporary definition of sovereignty contains the duty to cooperate. In conclusion, the paper is going to reaffirm that making sovereignty tougher in order to avoid cooperation certainly weakens the ability of the states to control what happens in their territories and, consequently, their sovereignty.

Keywords: international legal cooperation; sovereignty; human rights; new paradigms. 


\section{INTRODUÇÃO}

O Direito Internacional surgiu para regular as relações entre Estados, pois a natureza gregária dos seres humanos, aliada ao caráter sem-fim de suas necessidades, tornou inevitável o desenvolvimento de relações exteriores. Registros remotos transparecem que povos da Antiguidade já comerciavam entre si, editavam tratados com certa sofisticação e nomeavam representantes para tratar de seus interesses, sendo que, a partir do momento inicial, o intuito de cooperação para a satisfação de interesses mútuos sempre foi viés marcante do Direito Internacional.

Desde o primeiro acordo de cooperação que se tem notícia, que é o tratado de extradição firmado em 1280 a.C entre o faraó Ramsés II, do Egito, e Hatsuli, rei dos hititas (ARAÚJO JÚNIOR, 1994, p. 61), o auxílio mútuo contribuiu mais que qualquer outro instrumento para aproximar nações. A progressão dos contatos interestatais permite afirmar que não mais existe Estado absolutamente isolado, sendo conhecido que até mesmo a reclusa Coreia do Norte mantém diálogos cooperativos com a China para a satisfação de suas necessidades belicistas.

Por muito tempo, o traço mais marcante da cooperação foi possibilitar a extradição de pessoas e o cumprimento de cartas rogatórias criminais, aparato hoje reputado lento e ineficaz. Superando esse contexto, que se arrastou por tempo excessivo, no pós-guerra o cenário se transformou para conceber novas medidas de cooperação, agora não restritas apenas à aplicação de sanções criminais, como o auxílio direto, a cooperação via autoridade central (PIRES JÚNIOR, 2012, p. 15) e a formação de redes de cooperação internacional entre Ministérios Públicos. 
A forma como modernamente os Estados aplicam o Direito Internacional para solucionar as problemáticas transfronteiriças impôs à cooperação jurídica internacional transitar do singelo papel de instrumentalizar o Direito Penal Internacional para ser uma ferramenta essencial para a satisfação dos Direitos Humanos.

A efervescência com que pessoas e riquezas se deslocam pelo mundo, para mais de incrementar nossa qualidade de vida e aproximar culturas, potencializou o surgimento de problemas que não podem ser solucionados solitariamente por um único Estado (ALEGRE, 2011, p. 25).

A facilidade de trânsito forçou também a necessidade de agilidade na interlocução de informações entre Estados, e, por decorrência, a necessidade de se suavizar as restrições que as fronteiras imaginárias trazem, criando um novo paradigma para o secular conceito de soberania (SAADI; BEZERRA, 2012, p. 20).

Muito além da mera obtenção e compartilhamento de provas e traslado de pessoas processadas, o Direito Internacional passou a se ocupar da superação dos entraves infligidos pelas fronteiras em favor do implemento de direitos humanos, como o acesso ao meio ambiente ecologicamente equilibrado (Declaração de Estocolmo), a repatriação de crianças para suas famílias (Convenção de Haia sobre Aspectos Civis do Sequestro Internacional de Crianças), a preservação da dignidade de adotandos (Convenção relativa à Proteção das Crianças e à Cooperação em Matéria de Adoção Internacional) e a prestação de alimentos (Convenção de Nova Iorque Sobre Prestação de Alimentos no Estrangeiro), novas preocupações que evidenciam o giro de atuação aqui afirmado.

Também suplantou a burocrática via diplomática, caminho lento e cartorial tradicionalmente utilizado para formalizar a atuação conjunta 
de Estados em matéria criminal, possibilitando agora que autoridades centrais designadas nos tratados solicitem as medidas diretamente entre si, inclusive muitas vezes dispensando a participação do Poder Judiciário.

Dois exemplos da história brasileira recente ilustram bem a ruptura do modelo e a modernização da peculiaridade do Direito das Gentes que tratamos, não sendo demasia trazer que suas aplicações seriam absolutamente improváveis décadas atrás.

$\mathrm{O}$ primeiro deles, intimamente relacionado ao direito à preservação da própria história cultural e à intimidade genética, foi a repatriação de 2.693 frascos de sangue de índios ianomâmis de Roraima. O sangue, coletado na década de sessenta por cientistas estadunidenses sem autorização, foi trazido de volta ao Brasil por acordo firmado pela Secretaria de Cooperação Jurídica Internacional do Ministério Público Federal e a Pennsylvania State University, sendo enterrado após cerimônia funerária própria da cultura dos índios ianomâmi (MPF, 2016).

O segundo, cuja essência é preservar o direito ao meio ambiente ecologicamente equilibrado, foi a transferência dos Estados Unidos da América para o Brasil de sete filhotes de uma jiboia albina rara que foi contrabandeada daqui para lá em 2009. Após acordo de cooperação jurídica internacional celebrado entre os dois Estados, os filhotes do réptil foram repatriados em junho de 2015 (MPF, 2015).

O engrandecimento dos Direitos Humanos por intermédio da cooperação jurídica internacional, tônica das duas mencionadas hipóteses, é instituto legitimamente contemporâneo, e certamente apenas mostrou pequena fração de seu potencial até agora.

O mosaico de situações que podem ter soluções incrementadas pela cooperação jurídica internacional tem seus limites ampliados a todo tempo, ganhando cada vez mais corpo à medida que as relações humanas 
vão superando fronteiras, o que amplia sistematicamente a fluidez do tema e deixa contundente a necessidade de ampliação de estudos jurídicos pertinentes.

Nesse ambiente, a finalidade da soberania, instituto secular, está em constante mutação, sendo redesenhada conforme os Estados modernizam sua atuação face ao avançar das necessidades que somente podem ser resolvidas por intermédio do auxílio mútuo. Por isso, o intuito deste artigo é fazer breve digressão histórica da recente ampliação de rumos da cooperação jurídica internacional e analisar novas feições que a interação dinâmica conferiram à autoridade das nações.

\section{COOPERAÇÃO JURÍDICAINTERNACIONAL: AMPLIAÇÃO DE TEMAS}

O longo histórico de relações mantidas pelos Estados tornaram a praxe de cooperar um costume internacional, passando a ser fonte do Direito Internacional Público. Mas, quando foi alçada a tal status, a cooperação jurídica internacional ainda era visivelmente monotemática, precipuamente operacionalizando o Direito Penal Internacional via extradição e roga de produção de provas e de atos de comunicação processual. Na segunda metade do século XX, isso mudou.

O ser humano se move desde seu surgimento como espécie, mas o fenômeno da migração internacional massiva nem secular ainda é, pois emergiu em paralelo com o "[...] início do século XX e foi condicionado pela introdução de passaportes, vistos e outros instrumentos para regular quem é autorizado a cruzar as fronteiras nacionais e permanecer no país de acolhimento"(ALEGRE, 2011, p. 26).

Não que a transposição de fronteiras tenha sido alguma 
novidade naquele momento, mas a tentativa dos Estados se valerem de sua soberania para manter controle sobre a situação, e o avanço da problemática decorrente da circulação de pessoas e bens se tornou realidade após a primeira grande guerra.

A modernização dos transportes e das comunicações deixou o panorama ainda mais ágil. Uma viagem de transatlântico a vapor de Lisboa para o Rio de Janeiro durava 24 dias, hoje é feita via aérea em menos de 11 horas (PORTUGAL, 2001). Entre a encomenda e o recebimento de mercadorias oriundas de outros continentes era comum transcorrer mais de um mês, na atualidade dois dias são mais do que suficientes. Há um século, a transposição de informações era essencialmente física, na atualidade a remessa eletrônica de dados faz com que riquezas circulem por ondas eletromagnéticas pelo mundo num piscar de olhos. E tudo isso está muito mais barato.

O número de pessoas que circulam pelo mundo também aumentou exponencialmente. A explosão demográfica nos países subdesenvolvidos impulsionou novos fluxos migratórios de pessoas em busca de uma vida melhor. Ao lado disso, a redução do crescimento populacional e o aumento da expectativa de vida em países desenvolvidos tornaram indispensável a aceitação de mão de obra estrangeira para evitar ruínas na economia. Como resultado nada surpreendente, hoje temos 750 milhões de pessoas anualmente realizando viagens internacionais, carregando consigo seus bens e seus problemas (OIM, 2015).

A estrutura tornou indispensável a modernização na forma que os Estados interagem para viabilizarem a satisfação de seus interesses mediante a realização de atos além de suas fronteiras, afinal as concernentes demandas aumentaram sensivelmente.

A título de ilustração, temos que, entre a década de trinta e o ano 
de 2004, no Supremo Tribunal Federal foram distribuídas dez mil cartas rogatórias e sete mil sentenças estrangeiras. Em 2004 foi promulgada a Emenda Constitucional 45, que transferiu ao Superior Tribunal de Justiça a competência para processar cartas rogatórias e homologar sentenças estrangeiras e, somente entre 2005 e 2011, o tribunal recebeu seis mil cartas rogatórias e cinco mil sentenças estrangeiras (ARAÚJO, 2012, p. 37). Assim, com facilidade a demanda formal por cooperação jurídica na atualidade é $600 \%$ maior do que a verificada em meados do século passado.

O avançar do auxílio mútuo confunde-se com o progresso da globalização e a relativização da rigidez das fronteiras, fenômeno bem pontuado por Teubner (2006, p. 209):

[...] la globalización es un proceso policéntrico, en el que diversos ámbitos vitales superan sus límites regionales y constituyen respectivamente sectores globales autónomos. Es un fenómeno multidimensional que implica diversas áreas de actividad e interacción, incluyendo el campo económico, político, tecnológico, militar, cultural y medioambiental ${ }^{1}$.

A intensidade da globalização de mercados foi ambivalente à da internacionalização do crime organizado. A modernização impôs à cooperação internacional criminal o desenvolvimento de novas ferramentas, como a transferência temporária de pessoas, a transferência de execuções penais, a obtenção de provas via videoconferência e o auxílio direto.

1 Tradução livre: A globalização é um processo policêntrico, em que diversas áreas vitais superam seus limites regionais e constituem respectivamente setores globais autônomos. É um fenômeno multidimensional que implica diversas áreas de atividade e interação, incluindo o campo econômico, político, tecnológico, militar, cultural e ambiental. 
A faceta não criminal da cooperação jurídica internacional floresceu em paralelo à adaptação da cooperação internacional de natureza criminal, acompanhando também o reconhecimento da existência de direitos humanos e os desafios transfronteiriços de sua implementação.

Desde então, prevaleceu que, quando possível, a satisfação de direitos humanos não poderia se embasar apenas na precariedade do singelo compromisso de reciprocidade, afinal os interesses envolvidos não são apenas estatais, mas sim também das pessoas envolvidas, que são diretamente beneficiadas pelo ato cooperativo. Logo, essencial que a cooperação internacional tivesse amparo em instrumentos permanentes e solenes, principalmente para conferir-lhe maior estabilidade e solidez.

$\mathrm{O}$ caráter universal dos direitos humanos ${ }^{2}$ também tornou de rigor reconhecer que existia o dever inderrogável de cooperar, não se configurando mera cortesia ou liberalidade, mas sim decorrência direta do princípio da solidariedade universal.

Nesse ritmo, os países americanos formalizaram um dos primeiros - e, até então, o mais complexo - tratados que versavam sobre auxílio mútuo para a satisfação de direitos humanos. Trata-se da Convenção de Havana de Direito Internacional Privado, mais conhecida como Código Bustamante, internalizado no Brasil em 1929.

O código impõe a seus signatários o dever de conferir, grosso modo, garantias individuais e direitos civis idênticos a seus nacionais e a estrangeiros vinculados aos demais signatários ${ }^{3}$, atribuindo plena

2 Não desconhecemos que o debate entre universalistas e os relativistas é extremamente intricado, sendo dos temas mais cativantes da teoria geral dos direitos humanos, especialmente porque diretamente relacionado às razões de fundo desses direitos. Acreditando na importância da abertura do diálogo entre nações com culturas distantes para implementar os direitos humanos em sua plenitude, vamos nos fiar às razões dos universalistas, para quem tais direitos "[...] decorrem da dignidade humana, na qualidade de valor intrínseco à condição humana. Defende-se, nessa perspectiva, o mínimo ético irredutível - ainda que se possa discutir o alcance desse mínimo ético e dos direitos nele compreendidos" (PIOVESAN, 2012, p. 47).

3 Art. $1^{\circ}$ Os estrangeiros que pertençam a qualquer dos Estados contratantes gozam, no território dos 
eficácia extraterritorial a tais prerrogativas.

Também versa sobre direito à nacionalidade, à propriedade e conferiu status de regra de ordem pública internacional às suas disposições que estabeleciam o dever de prestar alimentos ${ }^{4}$ e reconheceu o dever de se disponibilizar assistência judiciária a estrangeiros ${ }^{5}$.

O caráter vanguardista do tratado já está bem evidenciado. Todavia, a disposição mais relevante ao tema versado é veiculada pelo art. 388 do código, pois autoriza que a solicitação de cooperação internacional seja transmitida por qualquer modo convencionado pelos Estados ${ }^{6}$, acenando grande informalidade no auxílio necessário à satisfação de direitos humanos. Como será visto adiante, a desburocratização da cooperação ainda não foi totalmente digerida no Brasil, restando evidente o caráter ainda moderno do dispositivo, que permanece como uma meta a ser perseguida.

Passada essa fase incipiente, não é exagero afirmar que a segunda metade do século XX foi palco de um giro contundente no progresso da cooperação jurídica internacional em matéria não penal, sendo aquele o

demais, dos mesmos direitos civis que se concedam aos nacionais. Cada Estado contratante pode, por motivo de ordem pública, recusar ou sujeitar a condições especiais o exercício de determinados direitos civis aos nacionais dos outros, e qualquer desses Estados pode, em casos idênticos, recusar ou sujeitar a condições especiais o mesmo exercício aos nacionais do primeiro. Art. $2^{\circ}$ Os estrangeiros que pertençam a qualquer dos Estados contratantes gozarão também, no território dos demais, de garantias individuais idênticas às dos nacionais, salvo as restrições que em cada um estabeleçam a Constituição e as leis. As garantias individuais idênticas não se estendem ao desempenho de funções públicas, ao direito de sufrágio e a outros direitos políticos, salvo disposição especial da legislação interna.

4 Art. 68. São de ordem pública internacional as disposições que estabelecem o dever de prestar alimentos, seu montante, redução e aumento, a oportunidade em que são devidos e a forma do seu pagamento, assim como as que pró́bem renunciar e ceder esse direito.

5 Art. 382. Os nacionais de cada Estado contratante gozarão, em cada um dos outros, do benefício de assistência judiciária, nas mesmas condições dos naturais. Art. 383. Não se fará distinção entre nacionais e estrangeiros, nos Estados contratantes, quanto à prestação de fiança para o comparecimento em juízo. Art. 384. Os estrangeiros pertencentes a um Estado contratante poderão solicitar, nos demais, a ação pública em matéria penal, nas mesmas condições que os nacionais.

6 Art. 388. Toda diligência judicial que um Estado contratante necessite praticar em outro será efetuada mediante carta rogatória ou comissão rogatória, transmitida por via diplomática. Contudo, os Estados contratantes poderão convencionar ou aceitar entre si, em matéria cível ou comercial, qualquer outra forma de transmissão. 
instante em que sua autonomia foi indiscutivelmente conquistada.

Alguns instrumentos internacionais debatidos e editados naqueles anos conferem bastante solidez ao giro de aplicação aqui afirmado.

Aprimeira referência é a Declaração de Estocolmo de 1972, ponto de partida para a elaboração do atual sistema internacional de proteção ambiental. Quebrando paradigmas puramente desenvolvimentistas então ascendentes, adotou postura conciliatória, afirmando ser o meio ambiente equilibrado essencial para o bem-estar das pessoas e para o gozo de direitos humanos, reconhecendo que os esforços na área deverão ser comuns entre governo e sociedade e recorrendo à cooperação internacional para atingir sua finalidade ${ }^{7}$.

Já a Convenção de Haia sobre Aspectos Civis de Sequestro de Crianças (Convenção de Haia) fundamenta-se na necessidade de proteger as prerrogativas superiores das crianças e de defendê-las dos efeitos deletérios decorrentes da alteração de domicílio ou de retenções ilícitas.

O espírito central do tratado é a defesa dos direitos humanos das crianças deslocadas ilicitamente, via ações estatais conjuntas organizadas a partir de autoridades centrais, no objetivo de localizá-las e repatriá-las, amigavelmente ou, caso inviável, coercivamente, pela via administrativa ou judicial $^{8}$.

7 Também se requer a cooperação internacional com o fim de conseguir recursos que ajudem aos países em desenvolvimento a cumprir sua parte nesta esfera. Há um número cada vez maior de problemas relativos ao meio ambiente que, por ser de alcance regional ou mundial ou por repercutir no âmbito internacional comum, exigem uma ampla colaboração entre as nações e a adoção de medidas para as organizações internacionais, no interesse de todos. A Conferência encarece aos governos e aos povos que unam esforços para preservar e melhorar o meio ambiente humano em benefício do homem e de sua posteridade.

8 Artigo $7^{\circ}$ - As autoridades centrais devem cooperar entre si e promover a colaboração entre as autoridades competentes dos seus respectivos Estados, de forma a assegurar o retorno imediato das crianças e a realizar os demais objetivos da presente Convenção. Em particular, deverão tomar, quer diretamente, quer através de um intermediário, todas as medidas apropriadas para: a) localizar uma criança transferida ou retida ilicitamente: b) evitar novos danos à criança, ou prejuízos às partes interessadas, tomando ou fazendo tomar medidas preventivas; c) assegurar a entrega voluntária da criança ou facilitar uma solução amigável; d) proceder, quando desejável, à troca de informações relativas à situação social da criança; e) 
Outro instrumento que engrandeceu a cooperação jurídica na defesa dos direitos humanos foi a Convenção de Nova Iorque sobre Cobrança de Alimentos no Estrangeiro. O incremento do frenesi migratório terminou por distanciar credores e devedores de alimentos, sendo usual a delicada situação de estarem em Estados diferentes, emergindo dificuldades procedimentais significativas para assegurar satisfação do adimplemento do débito.

O principal objetivo do tratado é regular a cooperação entre os Estados para assegurar a cobrança de alimentos quando quem os deve mora além das fronteiras do domicílio do alimentando, protegendo sua dignidade. É aplicável tanto à homologação de uma sentença referente a alimentos ou a seu cumprimento, ou ainda ao início da ação concernente no Estado de domicílio do devedor.

Relevante novidade da convenção foi a possibilidade de autoridades intermediárias estabelecerem contatos diretos entre si, sendo dispensadas de buscarem a via diplomática para a troca de informações. Aliás, na atualidade a comunicação oficial pode se dar inclusive pela internet, tendo os documentos transmitidos presunção de legitimidade, dispensando-se autenticações.

Também com o escopo de imprimir proatividade nas interações interestatais, a convenção autoriza a instituição intermediária a transigir com o devedor. Para que os direitos humanos sejam satisfeitos de maneira arrojada, essencial que a fidúcia prevaleça nas relações internacionais, e aqui se tem um bom exemplo da aplicação do princípio da confiança,

fornecer informações de caráter geral sobre a legislação de seu Estado relativa à aplicação da Convenção; f) dar início ou favorecer a abertura de processo judicial ou administrativo que vise ao retorno da criança ou, quando for o caso, que permita a organização ou o exercício efetivo do direito de visita; g) acordar ou facilitar, conforme as circunstâncias, a obtenção de assistência judiciária e jurídica, incluindo a participação de um advogado; h) assegurar no plano administrativo, quando necessário e oportuno, o retorno sem perigo da criança; i) manterem-se mutuamente informados sobre o funcionamento da Convenção e, tanto quanto possível, eliminarem os obstáculos que eventualmente se oponham à aplicação desta. 
eis que um Estrado transfere ao outro a aptidão para ajuizar ação, obter provas e negociar direitos essencialíssimos de seus nacionais.

Quarta referência do giro de incidência da cooperação internacional é a Convenção relativa à Proteção das Crianças e à Cooperação em Matéria de Adoção Internacional, concluída em 1993. O principal objetivo do tratado é estabelecer garantias a fim de que as adoções transnacionais observem o superior interesse da criança e seus direitos humanos reconhecidos pela ordem internacional.

Nesse intuito, a convenção desenvolveu um sistema de cooperação internacional para assegurar as prerrogativas do adotante e prevenir o tráfico de crianças. O escopo do auxílio mútuo é permitir que a criança tenha desenvolvimento harmonioso no seio da família estrangeira que a adotar e, para isso, prevê instrumentos para potencializar as oportunidades de adoção internacional com respeito aos direitos fundamentais.

Organizando o sistema, o tratado traz que as autoridades centrais devem se amparar vividamente, removendo obstáculos para a aplicação da convenção, trocando informações, combatendo práticas vedadas dentro do processo (por exemplo, a obtenção de vantagens econômicas) e o acompanhamento dos concernentes processos.

Enfim, naquele período marcante a cooperação jurídica internacional progrediu de mero expediente coadjuvante do Direito Penal Internacional, adquirindo perfil multifacetado que, dentre suas finalidades, tem em mira a satisfação eficiente dos direitos básicos das pessoas.

Decerto o instituto ainda está longe de atingir todo o seu potencial, pois o formato atual ainda tem muito para ser aprimorado. A despeito dos avanços sensíveis, tem-se que ainda falta bastante pragmatismo na 
assistência jurídica, e o modelo precisa estar em constante adaptação para acompanhar as celeumas originadas pelo constante avançar da ciência e da celeridade cada vez maior da tramitação de informações ao redor do globo.

Quanto à ampliação da eficiência dos atos de cooperação, viável antecipar que, em período não muito distante, o caminho a ser adotado na interação cooperativa entre nações é a edição de tratados multilaterais que aproximem os procedimentos adotados entre os Estados, a exemplo do que já é parcialmente realidade na integração regional da União Europeia.

Perspectiva factível será a tentativa de implementação das conclusões do Conselho Europeu de Tampere em 1999 que, para a implementação das metas de liberdade, segurança e justiça (objetivos essenciais da perspectiva internacional dos direitos essenciais das pessoas), prevê políticas cooperativas de concessão de refúgio, ampliação de acesso à justiça, uniformização de procedimentos internos e definição de prioridades e objetivos comuns no aprimoramento dos direitos humanos.

Saindo do factível para o plano idealista, temos que seria extremamente eficiente a adoção do modelo de integração intergovernamentalista liberal, a fim de que os Estados conjuntamente desenvolvam proposições concretas comuns sobre seu destino econômico e político.

Acerca das teorias do intergovernamentalismo na União Europeia, anotam Ramos, Jesus e Marques (2009, p. 70):

[...] tal abordagem vê a União Europeia como um regime intergovernamental exitoso desenhado para administrar a interdependência econômica através de políticas negociadas de coordenação. Ou seja, 
os Estados, na qualidade de atores racionais, usam, de maneira instrumental, as instituições da União Europeia e transferem parte de sua soberania a fim de aumentar a eficiência da cooperação interestatal [...].

Certamente a atuação coordenada em tal nível é algo muito distante, afinal sequer foi atingida em nível regional até agora. De todo modo, depois de evidenciado que a cooperação internacional passou por onda de pluralização, é interessante proceder analisando os desafios vivenciados para a implementação do sistema ora vigente.

\section{DESAFIOS DA COOPERAÇÃO INTERNACIONAL CONTEMPORÂNEA: NOVO PADRÃO DE SOBERANIA E QUESTÕES AFINS}

Em seu perfil inicial, a sociedade internacional era integrada essencialmente por Estados soberanos, com aptidão para tratar com exclusividade das celeumas existentes em seu território, não se submetendo aos influxos de qualquer outro Estado ao fazê-lo. Daí surgiu o agora vetusto princípio da territorialidade da jurisdição, segundo o qual “[...] a autoridade dos juízes (e, portanto, das suas decisões) não pode extrapolar os limites territoriais do seu próprio país [...]” (SUPREMO TRIBUNAL FEDERAL, HC 102041/SP, Relator: Ministro Celso de Mello).

Em razão disso, sempre que precisar realizar ato que surta efeitos noutros territórios, deve o Estado se valer da cooperação jurídica internacional para atuar sem ferir assuntos internos de outrem. Trata-se de um poder de império auxiliando outro para a consecução de atos de interesse comum. 
Essa linha de ideias poderia induzir que cooperar no plano internacional é uma mera liberalidade das nações, que poderia fazê-lo ou não como bem entenderem. Todavia, a leitura moderna do auxílio mútuo internacional, principalmente quando envolver a implementação de direitos humanos, é bem diferente.

$\mathrm{O}$ conceito de soberania jamais foi um consenso, registrando grande fluência com o passar dos tempos.

No século XVI, Jean Bodin pioneiramente a concebia como “[...] o poder absoluto e perpétuo de uma República” (2011, p. 195). A perpetuidade era decorrente da ausência de limite temporal estabelecido previamente, e havia caráter absoluto porque nenhum integrante da República poderia impor limitações.

Aliás, antes de realizar essa conceituação no primeiro volume de sua célebre obra "Os Seis Livros da República", o pensador francês acenou a problemática da especificação jurídica do termo, havendo “[...] necessidade de formar a definição de soberania, porque não há jurisconsulto nem filósofo político que a tenha definido" ( BODIN, 2011, p. 196).

Com seu conceito, Bodin elaborou teoria geral balizadora da ação política e jurídica do Estado Moderno, que deveria guardar respeito às convenções e aos tratados.

Posteriormente, a paz de Westfália, que moldou a fisionomia atual do Estado, (DINIZ FILHO, 2003, p. 68) conferiu ainda mais rigidez à noção de soberania. Conforme Accioly $(2000$, p. 8):

A assinatura do Tratado de Westfália de 24 de outubro de 1648 pôs fim à Guerra dos Trinta Anos, que ensanguentou a Europa de 1618 a 1648 . O Tratado de Westfália marca o fim de uma era e o início de outra 
em matéria de política internacional, que estava em seus primórdios.

Nesse raciocínio, o tratado fortaleceu ainda mais a concepção de que os Estados monopolizam os poderes exercidos sobre seus territórios.

Os Estados estão cada vez mais conectados com os outros, de onde surge relação de forte dependência; o isolamento não é mais possível, e a aplicação cega do princípio da territorialidade da jurisdição pode levar a indesejável ostracismo.

A crise do clássico Estado nacional indica a premente necessidade dele se reinventar para poder desenvolver atividades de coesão social, inclusive conferindo nova vocação para o papel das fronteiras, sendo a cartografia cada vez menos rígida em benefício dos interesses das pessoas. O Estado está progressivamente flexibilizando sua soberania por intermédio de compromissos internacionais de defesa dos direitos humanos, implicando em redução do poder nacional e majoração do poder supranacional (RAMOS, 2015, 119).

Traduzindo o raciocínio em outras palavras, “[...] o mundo das soberanias caminha para um mundo das pessoas, esbatendo-se as tradicionais fronteiras políticas e consolidando-se novos conceitos como a responsabilidade de proteger as pessoas das violações mais graves de direitos humanos" (ALEGRE, 2011, p. 25). A definição contemporânea de soberania encerra o dever cogente de cooperar, e a tendência é que tal mister se aprofunde nas próximas décadas.

Sobre isso, Vieira (2015, p. 290) arremata:

[...] o novo conceito de soberania compreende a noção de cooperação institucional entre os Estados, participantes de instituições e organizações internacionais, acordantes em tratados internacionais, 
que têm o poder de alcançar conjuntamente metas antes só imaginadas pelos Estados individualmente considerados, exercendo grande influência na determinação política e econômica de cada Estado. Peter Häberle faz uma reflexão sobre o Estado Constitucional que muda de papel: de nacional passa a ser cooperativo, provocando uma relativização do próprio dogma da soberania nacional. Assim, o Estado Constitucional assume a 'cooperação' como parte de sua identidade, de forma documentada, entrelaçando as relações internacionais e supranacionais, numa percepção de cooperação e responsabilidade internacional, bem como da solidariedade, tendo como finalidade atingir 'políticas de paz'. Esse novo Estado serve a uma sociedade 'aberta', sem fronteiras, com 'cidadãos do mundo', em oposição ao 'Estado individualista', totalitário, que se volta a uma 'sociedade fechada'.

Emerge que as soberanias, vendo-se bastante limitadas por não poderem resolver interesses nacionais relevantes em razão de outras soberanias, terminaram por deixar seu viés absolutista de lado para cumprir a obrigação de cooperar cada vez mais efusivamente. $\mathrm{O}$ poder estatal não pode servir para acobertar violações a direitos humanos, devendo o auxílio mútuo moderno ter potencial para contornar tal instituto secular para corrigir injustiças.

Mais do que isso, cooperar passou a ser um dever decorrente do princípio da solidariedade universal e da noção de justiça universal. Ao menos formalmente, o Brasil assimilou bem a ideia, pois a Constituição "[...] assinala essa evolução que converteu a cooperação interetática numa obrigação internacional, tanto que a Carta consagra entre os princípios da República a cooperação entre os povos para o progresso da humanidade, 
diretriz na qual se insere o auxílio mútuo [...]" (ARAS, 2015, p. 242).

A bem da verdade, o processo de cooperação é fenômeno irreversível essencial para o desenvolvimento dos Estados, tendo a experiência da União Europeia comprovado como uma integração bem conduzida pode levar a resultados sociais, políticos e econômicos de qualidade.

Tendo presente que, no cenário de colaboração internacional, o Brasil demanda muito mais do que é demandado, o comando constitucional é a materialização da necessidade de conferir contornos mais sutis à soberania para satisfazer as próprias necessidades.

No aspecto, o Departamento de Recuperação de Ativos e Cooperação Jurídica Internacional do Ministério da Justiça registrou que, "[...] do total de pedidos de cooperação jurídica tramitados em 2010 e 2011, mais de $85 \%$ saíram do país e se dirigiram a uma autoridade estrangeira"(PIRES JÚNIOR, 2012, p. 16), sendo certo que a tendência se repetiu daquele período em diante, principalmente em razão das grandes investigações envolvendo organizações criminosas levadas a efeito de 2014 em diante.

Aliás, enrijecer a soberania para obstar a cooperação jurídica internacional pode ter, paradoxalmente, um efeito reverso, enfraquecendo o poder dos Estados de controlar o que acontece em seus territórios. Tomando um país de dimensões continentais como o Brasil por referência, temos por certo que nosso Estado desconhece a maior parte dos atos que se passam em seu território, controlando apenas fração ínfima das condutas aqui efetivadas.

Partindo dessa premissa, temos que, quanto mais rigor for imposto nos pedidos de cooperação internacional direcionados ao Brasil, maior será o índice de informalidade de efetivação de tais atos à revelia 
do Estado.

Se o Estado estrangeiro tem ciência de que o Brasil não está disposto a cooperar, poderá se valer de procedimentos informais de coletas de prova dentro de nosso território, sem que o Poder Judiciário, o Ministério Público ou o Ministério da Justiça tenham ciência de tal ato (ARAS, 2015, p. 249).

Como exemplo, suponha-se que uma nação adotante de procedimentos investigatórios bastante informais solicite ao Brasil a oitiva de testemunhas, e o pleito seja negado com invocação do princípio da territorialidade da jurisdição. Admitindo o ordenamento jurídico daquele país a coleta de prova oral em campo diretamente pela polícia, bastará para o propósito que um investigador seu ouça diretamente as testemunhas dentro do nosso território e confeccione relatório da evidência produzida. Nessa situação ilustrativa, o Brasil sequer saberá da produção dos atos em seu território, em claro desprestígio à sua soberania.

Todavia, o Estado brasileiro ainda está assimilando seu novo papel no cenário internacional, ainda perdurando lampejos simpáticos à concepção primitiva da invocação da soberania como óbice ao dever de cooperar. A título de referência, mencionamos passagem das notas taquigráficas do julgamento proferido pelo Supremo Tribunal Federal no $\mathrm{HC} 85.588 / \mathrm{RJ}$ :

O Sr. Ministro Ricardo Lewandowski - Senhor Presidente, com todo o respeito, entendo que estaríamos abrindo um precedente gravíssimo, porque é um atentado à soberania nacional. Ao se admitir, a pretexto de cooperação internacional, que se superem as formalidades para o exequatur de uma carta rogatória, realmente abriríamos um precedente perigoso e estaríamos legitimando qualquer tipo 
de ingresso de autoridade estrangeira no território nacional para praticar o ato que quiser, com todo o respeito.

Em nosso entender, ao contrário do afirmado na citação acima, tentar prestigiar cegamente a soberania, sem ponderar os interesses em jogo e entronizando burocracia desmedida, acaba por menosprezar o Estado acreditado. A soberania deve ser utilizada como elemento de aproximação de nações, e não o contrário, sendo a implementação dos direitos humanos o fundamento essencial dessa redução de distâncias.

A respeito, pondera Mazzuoli (2002, p. 173):

A verdadeira soberania deveria consistir numa cooperação internacional dos Estados em prol de finalidades comuns. Um novo conceito de soberania, afastada sua noção tradicional, aponta para a existência de um Estado não isolado, mas incluso numa comunidade e num sistema internacional como um todo. A participação dos Estados na comunidade internacional, seguindo-se essa nova trilha, em matéria de proteção internacional dos direitos humanos, esta sim seria sobretudo um ato de soberania por excelência.

Tal contexto supera completamente a justificativa inicial da cooperação jurídica internacional, que, como relembra Aras, era o "medo dos bárbaros", uma "[...] espécie de xenofobia jurídica que temia a cooperação penal com outras nações e insistia na autoafirmação da soberania do país" (2015, p. 245).

O verdadeiro pretexto do auxílio mútuo contemporâneo deve ser a confiança a partir da solidariedade entre as nações, o que evidentemente conferirá simplificação dos meios e redução de formalismos e, por 
decorrência, a segurança pretendida pelas pessoas na satisfação de seus direitos.

Ao se relacionarem, o elemento valorativo de identidade entre os Estados deve coincidir com o movimento de universalização dos direitos humanos, que, nos referidos tratados internacionais, revela um padrão de convergência no plano normativo (BECHARA, 2012, p. 51).

Agir mutuamente, hoje, não é ato discricionário, mas sim uma necessidade premente dos Estados. Por vezes, cooperar é tão urgente que mecanismos de decisão consensual, muito comuns nas organizações internacionais, são insuficientes, especialmente em razão da morosidade que os caracteriza, lentidão hodiernamente provocada pelas desigualdades que existem entre as nações (REIS, 1999, p. 291).

De se insistir que, no âmbito da nunca estanque definição de soberania, agora não mais se enxerga a autonomia absoluta do Estado conduzir todos os atos oficiais em seu território como traço marcante. Cooperar não é perda de soberania, ainda que parcial, mas sim o exercício dela em sintonia com os valores dos direitos humanos, ampliando-se conjuntamente os poderes estatais.

As afinidades compartilhadas pelas nações amistosas aos direitos humanos é a tônica da atuação internacional do Estado Pós-Moderno, e o agir sincronizado em atos de cooperação prestigia os direitos humanos e engrandece os Estados que o fazem.

\section{CONCLUSÃO}

A cooperação jurídica internacional se transformou muito rapidamente de hermético mecanismo de extradição de pessoas e de produção de provas criminais em método proativo de superação de limites 
estatais para garantir o implemento de direitos humanos.

$\mathrm{Na}$ atualidade, o que um Estado tem em mira rogar cooperação para outro não necessariamente é a produção de atos tendentes a reprimir conduta penalmente relevante, sendo cada vez mais volumoso o conjunto de direitos de primeira e segunda geração satisfeitos via auxílio mútuo.

Essa transformação impôs adaptações na sempre dinâmica definição de soberania, que, em razão da hipossuficiência dos EstadosNação em solver os problemas oriundos da globalização, transitou do conceito clássico westfaliano para, na virada do milênio, flertar com integrações regionais. Tais interações, caso desenvolvidas com sinergia adequada, terminarão por potencializar consideravelmente o poder dos atores estatais envolvidos.

A nova faceta da soberania está sendo paulatinamente absorvida pelos Estados, que estão passando a admitir maior permeabilidade em suas fronteiras, a fim de ampliarem seu poderio no cenário internacional e de satisfazerem os direitos essenciais de seus nacionais.

\section{REFERÊNCIAS}

\section{ACCIOLY, Hildebrando. Manual de Direito Internacional Público.} 14 ed. São Paulo: Saraiva, 2000.

ALEGRE, Isabel Burke de Lara Alegre. Globalização vs. segurança. In: Globalização, justiça e segurança humana. Brasília: ESMPU, 2011.

ARAS, Vladimir. Direito probatório e cooperação jurídica internacional. In: SALGADO, Daniel de Resende; QUEIROZ, Ronaldo Pinheiro de. A prova no enfrentamento à macrociminalidade. Salvador: Jus Podivm, 2015. 
ARAUJO, Nádia de. A importância da cooperação jurídica internacional para a atuação do estado brasileiro no plano interno e internacional. In: BRASIL. Ministério da Justiça. Manual de cooperação jurídica internacional e recuperação de ativos. Brasília, 2012.

ARAÚJO JUNIOR, João Marcello. Extradição: alguns aspectos fundamentais. Revista Forense, Rio de Janeiro, v.32b, n. 90, abril/jun 1994.

BECHARA, Flávio Ramazzini. Cooperação jurídica internacional: equilíbrio entre eficiência e garantismo. In: BRASIL. Ministério da Justiça. Manual de Cooperação Jurídica Internacional e Recuperação de Ativos. Brasília, 2012.

BODIN, Jean. Os Seis Livros da República. Livro Primeiro. São Paulo: Ícone, 2011.

DINIZ FILHO, Arthur José de Almeida. Padrões de dominação nas relações internacionais contemporâneas. In: BOUCAULT, Carlos Eduardo de Abreu e MALATIAN, Teresa. Políticas migratórias: fronteiras dos direitos humanos no século XXI. Rio de Janeiro: Renovar, 2003.

MAZZUOLI, Valério de Oliveira. Soberania e proteção internacional dos direitos humanos: dois fundamentos irreconciliáveis. Revista de informação legislativa. Brasília, v. 39, n. 156, p. 169-177, out/dez 2002.

MINISTÉRIO PÚBLICO FEDERAL (MPF). Brasil consegue repatriação de filhotes de serpente rara contrabandeada. 2015. Disponível em <http://noticias.pgr.mpf.mp.br/noticias/noticias-do-site/ copy_of_geral/brasil-consegue-repatriacao-de-filhotes-de-serpente- 
rara-contrabandeada >Acesso em 25 jun. 2016.

MINISTÉRIO PÚBLICO FEDERAL (MPF). Em cerimônia, índios Yanomâmis enterram sangue repatriado dos Estados Unidos. 2016. Disponível em <http://6ccr.pgr.mpf.mp.br/destaques-do-site/ em-cerimonia-indios-yanomamis-enterram-sangue-repatriado-dosestados-unidos/ >. Acesso em 25 jun. 2016.

ORGANIZAÇÃO INTERNACIONAL PARA MIGRAÇÕES (OIM). Uma em cada sete pessoas no mundo é migrante ou refugiada. 2015. Disponível em $<$ http://agenciabrasil.ebc.com.br/internacional/ noticia/2015-12/uma-em-cada-sete-pessoas-no-mundo-e-migrante-ourefugiada-diz>. Acesso em 28 jun. 2016.

PIOVESAN, Flávia. Direitos Humanos e justiça internacional. 3 ed. São Paulo: Saraiva, 2012.

PIRES JUNIOR, Paulo Abrão. O papel da cooperação jurídica internacional. In: BRASIL. Ministério da Justiça. Manual de Cooperação Jurídica Internacional e Recuperação de Ativos. Brasília, 2012.

PORTUGAL. Museu das Migrações e da Comunidade. Viagem no Atlântico Sul. 2001. Disponível em <http://www.museu-emigrantes. org/a-memoria/memorias-de-viagem/por-mar.html>. Acesso em 28 jun. 2016.

RAMOS, Leonardo; MARQUES, Sylvia Ferraira; JESUS, Diego Vieira Santos de. A União Europeia e os estudos de integração regional. Belo Horizonte: Del Rey, 2009.

RAMOS, Mariana dos Anjos. O paradigma da soberania e a cooperação jurídica internacional. In: RAMOS, André de Carvalho; MENEZES, Wagner. Direito Internacional Privado e a nova cooperação jurídica internacional. Belo Horizonte: Arraes Editores, 
2015.

REIS, Marcio Monteiro. O Estado contemporâneo e a noção de soberania. In: Anuário Direito e Globalização do Programa Interdisciplinar Direito e Globalização - UERJ, Vol. 1. Rio de Janeiro: Renovar, 1999.

SAADI, Ricardo Andrade; BEZERRA, Camila Colares. A autoridade central no exercício da cooperação jurídica internacional. In: BRASIL. Ministério da Justiça. Manual de Cooperação Jurídica Internacional e Recuperação de Ativos. Brasília, 2012.

TEUBNER, Gunther. Globalización y constitucionalismo social: alternativas a la teoría constitucional centrada en el Estado. In: Boletin Oficial del Estado y Facultad de Derecho de la Universidad Autónoma de Madrid. Madri : Boletim Oficial del Estado, 2006, p. 209.

VIEIRA, Andréa Costa. A cooperação jurídica internacional numa era de defesa dos direitos humanos. In: RAMOS, André de Carvalho; MENEZES, Wagner. Direito Internacional Privado e a Nova Cooperação Jurídica Internacional. Belo Horizonte: Arraes Editores, 2015.

Como citar: OLIVEIRA, Henrique Gentil. AGUIAR, Julio Cesar de. Novos paradigmas da cooperação jurídica internacional e o conceito contemporâneo de soberania. Revista do Direito Público, Londrina, v. 12, n. 2, p. 77-103, ago. 2017. DOI: 10.5433/1980-511X.2017v12n2p77

Recebido em: 28/06/2017

Aprovado em: 12/04/2017 